\title{
Diretrizes para o desenvolvimento de recursos táteis e sonoros em museus
}

Guidelines for the development of tactile and sonorous resources in museums

CARDOSO, Eduardo; Universidade Federal do Rio Grande do Sul

eduardo.cardoso@ufrgs.br

SILVA, Tânia Luisa Koltermann; Universidade Federal do Rio Grande do Sul

tania.koltermann@ufrgs.br

\section{Resumo}

O presente artigo expõe diretrizes para o desenvolvimento de recursos táteis e sonoros para promoção da experiência multissensorial por pessoas com deficiência visual em museus. Parte do procedimento metodológico de observação direta para compreender a experiência de pessoas com deficiência visual em museus com vistas a identificar e analisar os processos e tecnologias disponíveis para produção desses recursos. Para tanto, foram definidos sete locais para realização do estudo de campo: Pinacoteca do Estado de São Paulo, Museu do Futebol e Exposição Sentir para Ver; Museu Tiflológico (Madri); Museu da Batalha e Museu do Azulejo (Portugal); Museu Tátil Omero (Itália). Como resultado final foram elaboradas cinquenta e três diretrizes para eliminação de barreiras, promovendo a liberdade, o respeito e a autonomia a todos em museus.

Palavras Chave: museu; diretrizes; acessibilidade.

\begin{abstract}
The present article exposes guidelines for the development of tactile and sonorous resources to promote multisensorial experience for people with visual impairment in museums. Therefore, depart of the direct observation methodological procedure to understand the experience of visually impaired people in museums in order to identify and analyze the processes and technologies available for the production of these resources. Seven sites were defined for the field study: Pinacoteca do Estado de São Paulo, Football Museum and Sentir pra Ver Exhibition; Tiflológico Museum (Madrid); Batalha Museum and Azulejo Museum (Portugal); Omero Tactile Museum (Italy). As a final result, were developed fifty-three guidelines for eliminating barriers, promoting freedom, respect and autonomy for all in museums.
\end{abstract}

Keywords: museum; guidelines; accessibility. 


\section{Introdução}

Advindos de um contexto de preservação e de testemunho da cultura material, os museus, inicialmente, exerceram um papel de guardiões de acervos de natureza artística e documental. Atualmente, porém, são locais de patrimônio, de coleções de objetos e artefatos tecnológicos, mas também de lazer, de prazer, de encantamento, de reflexão e de conhecimento. Para tanto, assumem uma função social de síntese e oferta do conhecimento de forma atrativa à todos, interagindo com o passado, presente e futuro na busca por mútua transformação.

Nesse processo de reciprocidade, a diversidade do público desafia estas instituições e seus profissionais a corresponderem às suas expectativas e, antes de tudo, às suas necessidades. E, para ser um ambiente acessível, aberto a todos, será indispensável o emprego de recursos para acessibilidade na comunicação, informação e fruição de seus espaços e peças neles contidos.

Consoante a isto, vislumbra-se a necessidade de uma comunicação baseada na multimodalidade, enquanto uso de vários modos semióticos e suas combinações, para a estimulação multissensorial como promotora de uma dinâmica lúdico-educativa para interação ativa com o museu e a apropriação por seus visitantes.

A linguagem visual ainda é a forma predominante nas estratégias de comunicação cultural e museológica. No entanto, o contexto demográfico elenca as pessoas com deficiência visual como o público em maior número no cenário nacional. Frente a esta situação, têm-se considerado igualmente importante possibilitar acesso a imagens ilustrativas e artísticas pelo emprego de recursos de acessibilidade como a adaptação tátil e a audiodescrição enquanto meios de tradução intersemiótica. Porém, é certo que diferem os objetivos de cada uma dessas propostas e isto influencia a forma como são estruturadas. No entanto, corroborando com Valente (2009, p. 61) estas propostas se deparam com um problema em comum: "como possibilitar a fruição de objetos culturais por meio de recursos multimodais, criados pelos que veem, para serem utilizados, de modo que possam ser entendidas e produzam sentido no contexto daqueles que não veem ou nunca viram?"

Conforme citado anteriormente, diferentes estratégias de comunicação são utilizadas, justificando a heterogeneidade destes materiais. Todavia, observa-se que diferentes opções de desenvolvimento influenciam a forma como estes recursos são elaborados e compreendidos.

Para tanto, busca-se, por meio da observação direta, compreender a experiência de pessoas com deficiência visual em museus e identificar e analisar os processos e tecnologias disponíveis para produção de recursos táteis e sonoros para acessibilidade em museus.

\section{Desenvolvimento}

A base teórica do presente trabalho estrutura-se a partir do modelo de relação sujeito e objeto em um determinado meio/contexto enquanto áreas que delimitam os campos disciplinares para fundamentação teórica da pesquisa. Ressalta-se ainda neste artigo a base da ciência da mente, cérebro e educação por meio dos aspectos fisiológicos, culturais e sociais, que podem influenciar a experiência vivenciada pelos sujeitos da pesquisa (VIVIAN, 2012; TOKUHAMAESPINOSA, 2008). 


\subsection{Sujeito: as pessoas com deficiência visual}

Dallasta (2005) ressalta que a problemática da deficiência acompanha a evolução da humanidade, uma vez que a circunstância de haver uma considerável parcela de pessoas com algum tipo de deficiência física ou sensorial não é recente.

Segundo o Censo Demográfico de 2010 (INSTITUTO BRASILEIRO DE GEOGRAFIA E ESTATísTICA, 2012), cerca de 23,9\% da população, ou seja, mais de 45 milhões de brasileiros, possuem algum tipo de deficiência, seja ela mais ou menos severa. A deficiência visual é a que mais acomete as pessoas no Brasil, onde 35.791.488 indivíduos possuem algum tipo de deficiência e 528.624 não conseguem enxergar de modo algum. Em nível mundial, segundo a Organização Mundial da Saúde (OMS), 15\% da população, ou seja, 1 bilhão de pessoas possui algum tipo de deficiência (ORGANIZAÇÃO MUNDIAL DA SAÚDE, 2010).

Segundo os indicadores da exclusão cultural do Programa Mais Cultura (BRASIL, 2007), apenas $13 \%$ dos brasileiros frequentam cinema alguma vez por ano; $92 \%$ dos brasileiros nunca frequentaram museus; $93,4 \%$ dos brasileiros jamais frequentaram alguma exposição de arte.

Todavia, mesmo com a garantia legal de igualdade e integração social aos cidadãos, na prática, as pessoas com deficiência sofrem para realizar as mais simples ações rotineiras. $\mathrm{O}$ que implica à sociedade discutir, pensar e contemplar acessibilidade com responsabilidade e consciência, salientando que muitas das soluções motivadas pela acessibilidade beneficiam também ao público sem deficiência.

\subsection{Meio: o Museu}

O estudo "Museus em Números", do Instituto Brasileiro de Museus (2011), do Ministério da Cultura (MinC), revela que o Brasil, que iniciou o século XX com 12 museus, já conta com mais de 3.000 instituições museais mapeadas atualmente. Destas, 1.500 responderam ao referido censo museológico. Essa pesquisa mostra que $50,70 \%$ dos museus possuem instalações destinadas a pessoas com deficiência. Contudo, desse percentual, menos de $10 \%$ se destinam a sistemas de comunicação, sinalização e conteúdos acessíveis.

Estando o museu a serviço da sociedade e do seu desenvolvimento, encontra-se a serviço da proteção e conservação do patrimônio e, também, do público, com ou sem deficiência. Santos (2009) destaca que, além disto, os museus devem adquirir, conservar, investigar, comunicar e expor a evidência material do homem e do que o rodeia, com o objetivo de estudar, educar e divertir. Portanto, a caracterização dos museus deste século os qualifica como um espaço cultural para um público cada vez mais heterogêneo e exigente. Esse perfil exige mudanças, pois já não basta acumular história e tempo, precisando estabelecer uma dinâmica ativa na busca e satisfação das necessidades de seus usuários.

Entendendo o museu enquanto "agente humanizador" do processo de desenvolvimento do homem e da humanidade, Bruno (2010) salienta que a profunda relação entre o homem e o objeto dentro do museu não depende apenas da comunicação das evidências do objeto, mas também do recinto do museu como agente da troca museológica. Essa troca ocorre pela administração, conservação e organização de novas maneiras de informação por meio da elaboração de discursos expositivos e estratégias pedagógicas (CADERNOS DE SOCIOMUSEOLOGIA, 1996).

$\mathrm{Na}$ perspectiva da passagem do sujeito passivo e contemplativo para o que age e 
transforma a sua realidade, preservar o patrimônio cultural aproxima-se cada vez mais de uma nova prática social, ressaltando a importância da inclusão da comunidade na dinâmica do museu (GABRIELE, 2014).

Acerca da gestão cultural no cenário brasileiro atual, o Plano Nacional de Cultura (PNC), em sua meta 29 , que trata especificamente da acessibilidade, propõe " $100 \%$ de bibliotecas públicas, museus, cinemas, teatros, [...] atendendo aos requisitos legais de acessibilidade e desenvolvendo ações de promoção da fruição cultural" (BRASIL, 2012, p. 84).

E, sobre as estratégias e ações para viabilizar o acesso, destacam-se a previsão e ampliação do "acesso à fruição cultural, por meio de programas voltados a crianças, jovens, idosos e pessoas com deficiência, articulando iniciativas [...] ações educativas e visitas a equipamentos culturais", visando assegurar que os equipamentos culturais ofereçam "infraestrutura, arquitetura, design, equipamentos, programação, acervos e atividades culturais qualificados e adequados às expectativas de acesso, de contato e de fruição do público, garantindo a especificidade de pessoas com necessidades especiais" (BRASIL, 2012, p. 190).

Assim, os museus devem promover: a acessibilidade; o desenvolvimento da autonomia; o diálogo; a oferta de experiências multissensoriais; e experiências significativas para todos. Em resposta a essas demandas e mudanças culturais, sociais e econômicas que ocorreram nas últimas décadas, novas áreas e abordagens no campo do design podem contribuir para essa dinâmica no ambiente museal.

\subsection{Objeto: a experiência multissensorial}

Frente aos avanços tecnológicos e à mudança do público, que se tornou mais diverso e ativo, os museus e, paralelamente, a expografia seguem novos caminhos. A partir da década de 1920, os museus de ciência europeus, por exemplo, passaram a oferecer a possibilidade de manusear determinados objetos, numa situação de participação física no processo de fruição e aprendizagem. A interatividade passa a ser um denominador comum nos museus de ciências e das mais diversas naturezas. Assim, os demais sentidos (tato, olfato e audição) passam a ser explorados na experimentação expográfica, reproduzindo sensações ao longo do discurso expositivo (ARAÚJO, 2004).

Para Sarraf (2013), no final do século XX e início do século XXI, os museus passaram a enfrentar mudanças políticas e de atuação, o que alguns teóricos chamam modernização, deixando para trás uma postura meramente depositária e conservadora em busca de uma atitude orientada ao público. Nesta nova realidade, é possível compreender a origem de algumas estratégias empregadas para "garantir a presença qualificada do público, que tem como características principais o acesso, a interação e a mudança da linguagem expositiva e dos produtos culturais" (SARRAF, 2013, p. 14).

Primo (2006) salienta que um novo caminho implica na renovação da escrita expográfica, adotando linguagens mais diretas, abertas e potencializadoras da reflexão crítica pelo visitante, por meio de concepções de museus que assumam processos de comunicação mais interativos, que façam apelo aos sentidos, às emoções, às memórias, onde a interdisciplinaridade é considerada um instrumento promotor da transformação. E enquanto veículo de comunicação interativa, opera pela apresentação sensível dos objetos expostos, em uma linguagem visual, audível ou tátil. 
Segundo Neves (2009), para um espaço cultural receber a todos deverá pensar antecipadamente em cada um, em que uma abordagem inclusiva à comunicação museológica preveja múltiplas soluções, flexíveis e adaptáveis a diferentes situações.

Entre as soluções mais empregadas, destacam-se: os audioguias, enquanto sistema eletrônico de tour personalizado; Língua Brasileira de Sinais (LIBRAS); Recursos táteis, que podem englobar maquetes táteis, taxidermia, réplicas e toque em artefatos originais, tais como artefatos arqueológicos; a audiodescrição, enquanto tradução das informações e mensagens visuais no meio sonoro; o texto ampliado, como recurso às pessoas com visão residual, a exemplo das pessoas com baixa visão; o Braille, enquanto sistema de escrita com pontos em relevo; e o closed caption, como sistema de transmissão de legendas que descreve os sons e falas presentes nas imagens e cenas. Assim, novas estratégias começam a ser empregadas para aproximação ao público geral por meio de novas oportunidades de percepção.

Nessa perspectiva, Araújo (2004, p. 306-307) afirma que a relação entre homem e objeto/realidade não se constitui apenas em um processo de comunicação, mas de "interação informativa, onde o homem se transforma pela apreensão da informação, e o objeto/realidade pela revitalização e ampliação de seu valor simbólico, em um processo contínuo e recíproco, constitutivo e constituidor". Assim, quando o objeto é comunicado de forma eficaz e didática, pode "gerar uma nova dimensão no contexto e tem o seu grau de pertencimento reativado" (GABRIELE, 2014, p. 46), fortalecendo um dos principais objetivos das instituições museológicas: a difusão do conhecimento para instigar a capacidade de reflexão e o questionamento.

Assim, uma abordagem multissensorial evita a exclusão pelo uso de informações em diversos níveis de complexidade e por distintos meios de comunicação, sejam elas visuais, sonoras, táteis, olfativas etc., para que os ambientes culturais cumpram melhor e mais eficazmente sua missão. Além disto, "é necessário dar às pessoas uma motivação para ir ao museu, tornando-o interessante e agradável pelo desenvolvimento de atividades que se relacionem com as vivências ou experiências da vida das pessoas" (MINEIRO, 2004, p. 71). De acordo com o propósito desta pesquisa, destacam-se os recursos táteis e sonoros, que serão aprofundados a seguir conforme delimitação do objeto de estudo.

\subsubsection{Ciência da mente, cérebro e educação}

Embasada na troca e compartilhamento de informações entre a psicologia, a pedagogia e a neurociência em prol do ensino e da aprendizagem, a ciência da mente, cérebro e educação procura facilitar o aprendizado a partir da união de conhecimentos multidisciplinares sobre o funcionamento do sistema nervoso, dos comportamentos humanos e das estratégias pedagógicas (VIVIAN, 2012).

Tokuhama-Espinosa (2008) mapeou esses conhecimentos a partir de três esferas: a pedagógica; a psicológica ou social; e, a neurobiológica. Para tanto, propôs dez diretrizes: 1 . Bons ambientes; 2. Sentido e Significado; 3. Memória; 4. Período de atenção; 5 . A natureza social do aprendizado; 6. Conexão corpo-mente; 7. Imersão orquestrada; 8. Processos ativos; 9. Metacognição; 10. Aprendendo ao longo da vida. Essas diretrizes foram propostas para a aplicação em situações educacionais presenciais, entretanto, busca-se aproximação ao contexto cultural com vistas a contribuir aos procedimentos metodológicos da pesquisa enquanto macro-categorias de análise e agrupamento das diretrizes propostas. 


\section{Processos metodológicos e análise dos resultados}

Para o desenvolvimento do presente trabalho foram realizados os procedimentos de observação direta e grupo focal. Posteriormente, foram relacionados à fundamentação teórica para elaboração e verificação das diretrizes.

\subsection{Observação Direta}

A observação direta foi planejada a partir da fundamentação teórica e de pesquisa prévia em um projeto piloto. Após, o roteiro de coleta de dados foi refinado para as coletas seguintes.

O número de iniciativas baseadas na interação multissensorial entre visitantes e obras de arte em ambientes culturais têm aumentado muito nos últimos anos em todo o mundo. Em âmbito nacional, não são tantas as iniciativas desenvolvidas até o momento, mas algumas se destacam, como a Pinacoteca do Estado de São Paulo, o Museu de Arte Moderna de São Paulo e o Museu do Futebol. Recentemente, outros locais têm mostrado excelentes iniciativas, tal como o Museu Biológico do Instituto Butantan e o Centro de Memória Dorina Nowill, entre outros.

Foram definidos sete locais para observação direta de acordo com os critérios de representatividade em seu contexto, facilidade de acesso e permissão para realização da pesquisa. Em âmbito nacional: Pinacoteca do Estado de São Paulo, o Museu do Futebol e a Exposição Sentir para Ver. E, em âmbito internacional: Museu Tiflológico da ONCE (Madri); Museu da Comunidade Concelhia da Batalha e Museu do Azulejo (Portugal); Museu Tátil Omero (Itália).

O primeiro local visitado foi o Museu do Futebol no Estádio do Pacaembu em São Paulo. Dentre tantos aspectos observados, destaca-se, a preocupação na concepção de um novo museu já acessível desde sua implantação, assim como a quantidade, diversidade e qualidade dos recursos de acessibilidade. Outro aspecto muito importante é a permanente participação das pessoas com deficiência na equipe da instituição pelo Programa Deficiente Residente. Essa efetiva participação contribui para a qualificação dos demais membros da equipe e para o desenvolvimento e verificação dos recursos desenvolvidos.

Na Pinacoteca do Estado de São Paulo chama a atenção o acolhimento ao visitante desde o espaço exterior do museu até as suas dependências internas, o que ocorre com o emprego de maquetes táteis e audiodescrição. Porém, a Pinacoteca tem apenas parte do seu acervo disponível ao toque e com todos os recursos de acessibilidade: a Galeria Tátil. Reconhecida como uma das primeiras instituições culturais do Brasil a promover a acessibilidade a todos os públicos pelo PEPE - Programa Educativo para Públicos Especiais, de a criação da museóloga Amanda Tojal, a Pinacoteca mantém seu prestigio e é referência na área da formação e qualificação de educadores em museus.

Na Exposição Sentir para Ver destaca-se a integração entre as iniciativas pedagógicas e de acessibilidade, formando um conceito único segundo os princípios do design universal por meio da experiência multissensorial visando permitir a participação efetiva e autônoma de todos os públicos. Empregam-se maquetes, diagramas táteis e superfícies em relevo para a apresentação de 14 obras. Os recursos sonoros consistem em audiodescrição com linguagem fácil e ambientação por meio de efeitos sonoros, músicas e poesias. Outro fator importante é qualidade do conteúdo acessível que encontra-se no site da exposição. 
Em contexto internacional, primeiramente, visitou-se o Museu do Azulejo, onde destacamse as adequações arquitetônicas realizadas na tentativa de tornar acessível uma edificação do ano de 1458, o antigo Mosteiro da Madre de Deus. Dentre os recursos de acessibilidade, destacam-se os artefatos táteis produzidos em cerâmica como os azulejos encontrados na instituição e as audiodescrições dos espaços, como a capela, e dos painéis em azulejos, onde contempla narrativas informativas, técnicas e poéticas para uma plena ambiência do visitante. Ainda são exploradas texturas na cerâmica para representar diferentes informações, assim como a progressão de complexidade das informações e orientação para a exploração tátil.

O Museu da Batalha, sob o slogan "um museu para todos", tem por base a promoção do território e do patrimônio material e imaterial, de forma a melhor servir a sua comunidade. Assim, todos os recursos disponíveis estão claramente informados desde o exterior do prédio até o seu site. Pode-se realizar a visita com audioguia com audiodescrição desde o começo do percurso expositivo, que é orientado por um trilho tátil no piso e por uma linguagem de formas táteis que informa, pelo rastreamento, quando se tem objetos e/ou recursos para serem tocados e novos pontos para a ativação das faixas de som. Outro ponto marcante é a forma poética como são narradas algumas das audiodescrições, com a participação de pessoas da comunidade e membros da equipe de projeto, fortalecendo assim os laços entre a instituição e comunidade.

O Museu Tiflológico de la ONCE - Organização de Cegos da Espanha, em Madri, é um local onde os visitantes podem ver e tocar todas as peças expostas. O prédio é completamente acessível em seus três pavimentos. No terceiro andar ficam os modelos táteis de monumentos arquitetônicos, sendo 19 de obras nacionais e 16 internacionais, e a exposição de obras de arte de artistas com deficiência visual. O espaço expositivo é muito qualificado, provendo a autonomia de seus visitantes. Todos as obras possuem legendas e informações adicionais em dupla leitura e audiodescrição, mobiliário acessível, com forma, altura, condições de aproximação e alcance adequados. Ainda há o uso de distintos materiais para representar as propriedades de diferentes superfícies e informações, assim como a utilização de maquetes em diferentes escalas e graus de detalhamento para apreensão progressiva das informações em seus diferentes níveis de complexidade.

Por fim, o Museu Tátil Omero tem por objetivo promover o crescimento e integração cultural de pessoas com deficiência visual e difundir entre eles o conhecimento da realidade. Com total de 3000 metros quadrados em quatro andares, atualmente, apresenta cerca de 150 obras da coleção permanente organizadas em ordem cronológica, incluindo réplicas de esculturas famosas da Grécia Clássica ao início do século XX feitas em gesso e resina; obras de arte contemporânea originais; e, modelos de arquitetura e achados arqueológicos. A exploração tátil começa de forma geral por toda a peça até se chegar aos detalhes. Mediadores orientam essa experiência e contribuem com informações adicionais e com lançamentos de questões, fazendo com que não sejam dadas apenas respostas, mas criadas perguntas para o visitante buscar, de forma aberta, as respostas por sua conta. Em apoio às descrições sonoras, tem-se textos em dupla leitura. Destacase a estratégia de uma seção introdutória preceder a exposição temática visando dar condições para a compreensão das partes estruturais que compõem e articulam o espaço.

\subsection{Grupo Focal e Apresentação dos Resultados}

Conforme Mesquita (2011), a interpretação é o principal meio pelo qual os museus comunicam o seu acervo e através do qual a atenção é despertada, a experiência vivida e os 
registros gravados na memória. Portanto, segundo as observações diretas realizadas, muitas são as estratégias que podem ser utilizadas para promover a fruição dos visitantes com deficiência visual por meio da equiparação de oportunidades. Fato essencial para que os visitantes possam realizar um bom processo interpretativo, tomando consciência da importância do contexto das obras expostas, das suas principais características e de seus significados.

Para verificação das diretrizes geradas realizou-se a atividade de grupo focal com seis especialistas: um engenheiro mecânico, um designer, uma historiadora, um museólogo, uma audiodescritor, uma brailista. Isto ocorreu, primeiramente, por meio de uma discussão coletiva e, após, por meio de um instrumento individual de avaliação contendo parecer específico para cada diretriz elaborada. Dentre os especialistas, duas pessoas tinham deficiência visual, uma com baixa visão e outra cega. Assim, primeiramente, foi realizada a descrição de todo o conteúdo visual e a leitura das diretrizes para, posteriormente, cada item ser discutido pelo grupo. Ressalta-se que os profissionais aceitaram participar da pesquisa espontaneamente via consulta e confirmação prévia e de acordo com o termo de consentimento livre e esclarecido coletado do dia da atividade.

Após, as considerações dos especialistas foram relacionadas e tabuladas. O Quadro 1 apresenta 53 diretrizes relacionadas com a classificação de Tokuhama-Espinosa (2008) e verificadas pelos especialistas segundo dezesseis categorias elencadas por Mesquita (2011): ambiente externo; ambiente interno; comunicação museológica; recursos táteis; recursos em áudio; painéis informativos e sinalização; publicações; atendimento ao público/acolhimento; ação educativa.

Quadro 01: Diretrizes para o desenvolvimento de recursos táteis e sonoros para pessoas com deficiência visual em museus.

\begin{tabular}{|c|c|c|}
\hline Categoria & $\begin{array}{l}\text { Classificação } \\
\text { Tokuhama-Espinosa }\end{array}$ & Diretriz \\
\hline \multirow{5}{*}{ 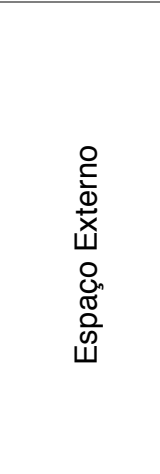 } & 1. Bons ambientes & $\begin{array}{l}\text { 1. A chegada ao museu (primeiro contato com o visitante) deve ser facilmente } \\
\text { identificada e sinalizada para correta orientação, incluindo o entorno próximo. }\end{array}$ \\
\hline & 1. Bons ambientes & $\begin{array}{l}\text { 2. O ideal é que a recepção seja próxima à entrada, assim como alguns serviços } \\
\text { essenciais, como os sanitários e elevadores. }\end{array}$ \\
\hline & $\begin{array}{l}\text { 5. Natureza social do } \\
\text { aprendizado }\end{array}$ & $\begin{array}{l}\text { 3. Os responsáveis pela recepção aos visitantes devem estar devidamente capacitados } \\
\text { para garantir um bom acolhimento a todos. }\end{array}$ \\
\hline & 3. Memória & $\begin{array}{l}\text { 4. As mesmas informações disponibilizadas ao público em geral devem ser garantidas } \\
\text { às pessoas com deficiência visual, porém através de outros meios (Braille, fontes } \\
\text { ampliadas e áudio). Assim como materiais adaptados a diferentes níveis de } \\
\text { compreensão e demais elementos (jogos e/ou equipamentos interativos). }\end{array}$ \\
\hline & 1. Bons ambientes & $\begin{array}{l}\text { 5. Os balcões de recepção devem apresentar sinalização que informe os recursos de } \\
\text { acessibilidade disponíveis. }\end{array}$ \\
\hline \multirow{5}{*}{ 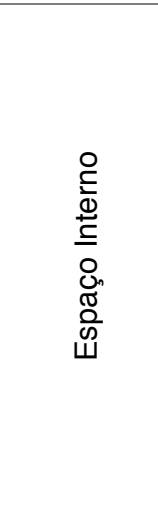 } & 1. Bons ambientes & $\begin{array}{l}\text { 6. Manter uma distribuição lógica dos ambientes e do percurso expositivo para fácil } \\
\text { orientação. } \\
\text { 7. Evitar desníveis, degraus e obstáculos suspensos não rastreáveis com a bengala. }\end{array}$ \\
\hline & 1. Bons ambientes & $\begin{array}{l}\text { 8. Empregar elementos táteis de piso, como pisos podotáteis, frisos guia ou corrimãos } \\
\text { para orientação de forma livre e autônoma. }\end{array}$ \\
\hline & 1. Bons ambientes & $\begin{array}{l}\text { 9. Para a iluminação, deve-se considerar o tipo de deficiência visual dos visitantes, } \\
\text { pois podem ter diferentes necessidades. Todavia, o contraste entre planos (piso e } \\
\text { parede) é essencial. }\end{array}$ \\
\hline & 2. Sentido e significado & $\begin{array}{l}\text { 10. Dispor de maquete tátil enquanto importante representação para o } \\
\text { reconhecimento do museu e construção da imagem mental do espaço. }\end{array}$ \\
\hline & $\begin{array}{l}\text { 1. Bons ambientes } \\
\text { 6.Conexão corpo- } \\
\text { mente }\end{array}$ & $\begin{array}{l}\text { 11. Disponibilizar espaços de descanso ao longo do percurso expositivo, assim como } \\
\text { equipamentos para auxílio à locomoção. }\end{array}$ \\
\hline
\end{tabular}




\section{Categoria Classificação Tokuhama-Espinosa}

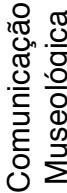

2. Sentido e significado

3. Memória

7. Imersão

orquestrada

2. Sentido e significado

\section{Período de atenção}

9. Metacognição

1. Bons Ambientes

2. Sentido e significado

2. Sentido e significado

2. Sentido e significado

10. Aprendizado ao longo da vida

1. Bons ambientes

\section{Memória}

2. Sentido e significado

3. Memória

2. Sentido e significado

2. Sentido e significado

2. Sentido e significado

3. Memória

2. Sentido e significado

3. Memória

8. Processos ativos

1. Bons ambientes

2. Sentido e significado

10. Aprendizado ao

longo da vida

2. Sentido e significado

7. Imersão

orquestrada

7. Imersão

orquestrada

\section{Diretriz}

12. Adotar uma postura semiótica, com a devida compreensão da concepção e da forma de como os objetos podem ser interpretados e de como obter a diversidade de interpretações e significados passíveis de serem resignificados (TOJAL, 2013). 13. Explorar diferentes técnicas e tecnologias com apelo aos sentidos de modo a criar conteúdos informativos, didáticos e lúdicos que despertem o interesse e se adaptem à diversidade de visitantes por meio da interação com os objetos e o contexto (MESQUITA, 2011; NEVES, 2009; TOJAL, 3013).

14. Selecionar peças/obras a serem transpostas por recursos táteis de maneira a representar bem o acervo da instituição - temática, período cronológico, estilo, materiais (TOJAL, 2013).

15. Considerar o tempo adequado para: o manuseio dos artefatos táteis; o número de peças a serem utilizadas; o número de visitantes por grupo; e até mesmo, a natureza do acervo.

16. A dimensão dos recursos táteis não deve exceder ao alcance dos braços. Obras muito pequenas devem ser ampliadas e obras muito grandes devem apresentar um modelo reduzido e/ou simplificado para primeira compreensão.

17. Utilizar materiais cujas propriedades sejam seguras ao toque. Caso contrário, o visitante deve ser devidamente alertado, a fim de que possa optar entre tocar ou não na peça.

18. Elaborar informações preparatórias para a experiência tátil, assim como materiais complementares para reduzir a possível diferença de compreensão das pessoas com diferentes graus de severidade de deficiência visual e/ou vivências nesse contexto.

19. As maquetes em escala não devem ultrapassar os limites de alcance dos braços e a escala deve ser informada.

20. Recorrer a diferentes texturas e materiais de forma a contribuir para a compreensão das formas e informações.

21. Respeitar os detalhes, como cores, formas e materiais específicos para a transposição da informação. Caso contrário, isto deve ser informado.

22. O acervo tátil deve ter sua localização facilmente identificada segundo o percurso podotátil ou demais elemento(s) de orientação espacial.

23. O trabalho em relevo deve ser simplificado de forma que a informação seja clara e objetiva.

24. Seguir uma lógica com gradativa evolução das informações conforme a complexidade das obras, mesmo que isso implique no uso de mais recursos em sequência.

25. Definir o material de réplicas de acordo com seu custo, durabilidade e manutenção.

26. Confeccionar réplicas no mesmo material que o original ou com propriedades semelhantes. Quando executada em material diferente do original, uma amostra deve der disponibilizada.

27. Escolher peças mais susceptíveis ao toque com segurança, tanta para a obra quanto para o visitante.

28. Para o toque em originais, o visitante deve obedecer aos critérios estabelecidos pelo museu. Normalmente, as mãos devem estar limpas e sem anéis e acessórios, ou mesmo com luvas.

29. Indica-se o uso de bancadas auxiliares ou tabuleiros estofados que permitam o apoio da peça durante o toque.

30. A inserção de áudios deve atender a todos, pois não destinam-se apenas às pessoas com deficiência sensorial, tendo assim uma linguagem fácil: simples e direta incluindo uma ideia principal por frase (MINEIRO, 2004).

31. As descrições devem ser pensadas em conjunto com os outros recursos/serviços, respeitando a obra enquanto expressão do autor e estabelecendo os elementos essenciais, equilibrando a relevância, adequação e economia no processo de descrição das imagens (NEVES, 2011).

32. Os equipamentos de áudio devem considerar a diversidade de usuários e o projeto expográfico, de forma a ser democrático, atrativo e com maior liberdade. 


\section{Classificação Tokuhama-Espinosa}

2. Sentido e significado

3. Memória

7. Imersão

orquestrada

7. Imersão

orquestrada

4. Período de atenção

7. Imersão

orquestrada

2. Sentido e significado

4. Período de atenção

2. Sentido e significado

8. Processos ativos

7. Imersão

orquestrada

9. Metacognição

2. Sentido e significado

2. Sentido e significado

ב⿱

3. Memória

1. Bons ambientes

3. Memória

33. Os audioguias devem permitir uma descrição sonora com informações históricas, culturais ou mesmo técnicas por meio de comentários que podem incluir também músicas, sons e descrições de imagens para ajudar o público a se situar na visita. 34. Considerar uma lógica para o desenvolvimento dos audioguias que proporcione autonomia aos visitantes, facilitando a compreensão, orientação espacial e deslocamento.

35. Criar uma interação dinâmica entre as palavras, a voz e os efeitos sonoros para o equilíbrio e harmonia entre as cargas informativas e expressivas da audiodescrição (NEVES, 2011).

36. De forma geral, deve-se começar por uma abordagem mais abrangente para então seguir ao detalhes, respeitando o tempo de assimilação para construção da imagem mental do objeto (MESQUITA, 2011).

37. Descrever as cores dos objetos/obras, pois as referências para as cores vão além da sua descrição visual, tendo cargas emocionais e culturais. Também pode-se descrever as qualidades táteis das cores para ajudar no processo de compreensão (MAGALHÃES E ARAÚJO, 2013).

38. Descrever com clareza e objetividade as suas dimensões e estrutura espacial. 39. Cuidar o tempo de audição por peça para não tornar a visita cansativa. Quando há a necessidade de uma maior duração, sugere-se que sejam divididas em diferentes faixas.

40. A descrição deve indicar a condição da peça/obra em exposição (se está em vitrina fechada, bancada, estado de conservação, etc.).

41. Os elementos interativos em telas acionadas pelo toque devem ter equivalente sonoro ou tátil da mesma atividade ou possibilitar ativação pelo toque em um dos cantos da tela (MINEIRO, 2011).

42. A combinação das linguagens visual e verbal contida nos vídeos pode contribuir muito para experiência de pessoas com dificuldade de leitura e compreensão de textos, porém, devem apresentar audiodescrição e legendas para pessoas com deficiências sensoriais (MESQUISA, 2011).

43. As versões audiovisuais devem respeitar o tempo de assimilação e compreensão das pessoas, desta forma empregando linguagem fácil e mantendo breves intervalos entre as falas/frase.

44. Cuidar o tamanho e tipo da fonte empregada em legendas, assim como o devido contraste com o fundo que estará por sobre.

45. A inserção da audiodescrição não deve sobrepor-se a sons gerando interferências nas mensagens.

46. Todos os elementos textuais devem ser disponibilizados no mínimo em dupla leitura (fonte ampliada e Braille), sempre respeitando a NBR 9050.

2. Sentido e significado 47. Imagens devem manter bom contraste e definição entre fundo e figura, além de empregar outros meios para transposição dessa mensagem. llustrações confusas devem ser evitadas, assim como as de pequeno tamanho devem ser total ou parcialmente ampliadas (MESQUITA, 2011). 48. A sinalização deve constituir uma cadeia de informações capazes de orientar o visitante, permitindo meios adequados para tomada de decisão com conforto e segurança, respeitando a NBR 9050.

3. Memória

49. As publicações devem ser disponibilizadas em formatos acessíveis - dupla leitura, em fonte ampliada e áudio (MESQUITA, 2011).

5. A natureza social do aprendizado
50. Os responsáveis pelo acolhimento ao público devem estar devidamente capacitados, atentos às diferenças, expressando-se de forma clara e objetiva e, quando necessário, acompanhando o visitante até que tenha condições de realizar a visita com conforto, segurança e autonomia (MESQUITA, 2011). 


\begin{tabular}{|c|c|c|}
\hline Categoria & $\begin{array}{c}\text { Classificação } \\
\text { Tokuhama-Espinosa }\end{array}$ & Diretriz \\
\hline \multirow{3}{*}{ 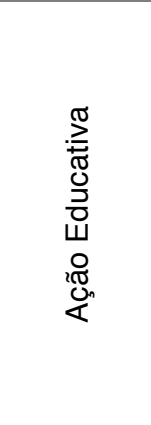 } & 8. Processos ativos & $\begin{array}{l}\text { 51. Os materiais lúdicos assim como recursos complementares devem ser } \\
\text { desenvolvidos por equipes interdisciplinares aliada à participação efetiva de pessoas } \\
\text { com deficiência. }\end{array}$ \\
\hline & $\begin{array}{l}\text { 7. Imersão } \\
\text { orquestrada } \\
\text { 8. Processos ativos }\end{array}$ & $\begin{array}{l}\text { 52. Os profissionais responsáveis pela comunicação e mediação no museu devem ter } \\
\text { uma compreensão clara das possibilidades de concepção e ampliação das condições } \\
\text { de interação das pessoas com deficiência com o acervo/ambiente da instituição } \\
\text { (TOJAL, 2013). }\end{array}$ \\
\hline & $\begin{array}{l}\text { 7. Imersão } \\
\text { orquestrada } \\
\text { 3. Memória }\end{array}$ & $\begin{array}{l}\text { 53. As estratégias de mediação deverão ampliar o uso dos canais perceptivos visando } \\
\text { uma ação educativa inclusiva (racional, responsável e responsiva) ao considerar a } \\
\text { diversidade de públicos e a forma como se apropriam dos objetos/espaços (TOJAL, } \\
2013, \text { p. } 36 \text { ). }\end{array}$ \\
\hline
\end{tabular}

Fonte: adaptado de Cardoso (2016)

Acerca da classificação de Tokuhama-Espinosa (2008), as diretrizes 1 (bons ambientes), 2 (sentido e significado), 3 (memória) e 7 (imersão orquestrada) são as que têm mais ocorrências na lista de diretrizes verificadas, levando-se a relacioná-las com os casos observados, onde a preocupação com a acessibilidade física e de conteúdo/comunicação é de maior importância.

\section{Considerações finais}

A partir do objetivo de contribuir para o desenvolvimento de recursos táteis e sonoros para acessibilidade em museus, as diretrizes elaboradas pela triangulação de dados proveniente da observação direta, da avaliação pelo grupo focal e do embasamento teórico, devem ser aplicadas para verificação por usuários com deficiência, assim como podem ser testadas em outros contextos além do cultural para o mesmo público.

Retomando a classificação de Tokuhama-Espinosa (2008) e as diretrizes com mais ocorrência, quanto ao ambiente físico (1), a segurança física e emocional é extremamente importante, não obstante, o respeito à individualidade, liberdade e autonomia das pessoas com deficiência visual, também são igualmente importantes. Acerca do sentido e significado (2), os conteúdos a serem transmitidos e experiências a serem ofertadas devem considerar as vivências e contexto dos visitantes, assim como a sua maneira de compreensão e apropriação. Tal como considerar que diferentes abordagens de comunicação podem tirar proveito dos distintos sistemas de memória (3), aumentando as chances de retenção das informações. Por fim, sobre a imersão orquestrada (7), dois aspectos são ressaltados: a importância da mediação para organização e orientação dos visitantes e como promotores da discussão e troca coletiva; e, o desafio de considerar a diversidade do público como uma oportunidade para combinar diferenças para promover a interação entre as pessoas de modo a maximizar as experiências de todos.

A partir da pesquisa realizada, cabe salientar a importância em proporcionar um ambiente livre de barreiras para que os visitantes sintam-se seguros para usufruir deste espaço/acervo com liberdade, respeito, autonomia e sem receio de sofrer constrangimentos, considerando-os ativos no processo de interpretação e construção do conhecimento de forma dinâmica e interativa pela oferta de novos desafios e pela reflexão sobre eles. 


\section{Referências}

ARAÚJO, M. M. Comunicação museológica: desafios e perspectivas. In: SEMINÁRIO DE CAPACITAÇÃO MUSEOLÓGICA, 2004, Belo Horizonte. Anais... Belo Horizonte: Instituto Cultural Flávio Gutierrez, 2004. p. 304-314.

BRASIL. Ministério da Cultura. As metas do Plano Nacional de Cultura. Brasília, DF, 2012. Disponível em: <http://www.fundacaocultural.ba.gov.br/colegiadossetoriais/As-Metas-do-PlanoNacional-de-Cultura.pdf>. Acesso em: 25 jun. 2014.

. Ministério da Cultura. Programa Mais Cultura. Brasília, DF, 2007. Disponível em: <http://www.cultura.gov.br/site/categoria/politicas/gestao-cultural/dados-da-cultura/>. Acesso em: 10 mar. 2007.

BRUNO, M. C. O. (Coord.). Waldisa Rússio Camargo Guarnieri: textos e contextos de uma trajetória profissional. A evidência dos contextos museológicos, v. 1. São Paulo: Pinacoteca do Estado/Secretaria de Estado da Cultura/ICOM, 2010.

DALLASTA, V. C. A situação das pessoas portadoras de deficiência física. Santa Maria, RS: Universidade Federal de Santa Maria, 2005.

CADERNOS DE SOCIOMUSEOLOGIA. Lisboa: Universidade Lusófona de Humanidades e Tecnologias, n. 9, 1996.

CARDOSO, E. Design para experiência multissensorial em museus: fruição de objetos culturais por pessoas com deficiência visual. 2016. 590 f. Tese (Doutorado em Design) - Programa de PósGraduação em Design (PgDesign) da Escola de Engenharia e Faculdade de Arquitetura da Universidade Federal do Rio Grande do Sul (UFRGS), Porto Alegre, 2016.

GABRIELE, M. C. F. L. Sociomuseologia: uma reflexão sobre a relação museus e sociedade. Expressa Extensão, Pelotas, Rio Grande do Sul, v. 19, n. 2, p. 43-53, 2014.

INSTITUTO BRASILEIRO DE GEOGRAFIA E ESTATÍ́STICA (IBGE). Censo 2012. Brasília, DF, 2012. Disponível em: <http://www.ibge.gov.br>. Acesso em: 15 dez. 2013.

INSTITUTO BRASILEIRO DE MUSEUS (IBRAM). Museus em números. Brasília, DF, 2011. Disponível em <http://www.museus.gov.br/IBRAM/doc/museus_numeros.pdf>. Acesso em: 11 fev. 2011.

MAGALHÃES, C. M., Araújo, V. L. S. (2012). Metodologia para elaboração de audiodescrições para museus baseada na semiótica social e multimodalidade: introdução teórica e prática. In: ALED Associação Latino-americana de Estudos do Discurso, Caracas, v. 1, n 12, pp. 31-55.

MESQUITA, S. M. V. (2011). Acessibilidade de Museus Europeus para Deficientes Visuais. Dissertação de Mestrado. Programa de Pós-Graduação em Gestão e Planeamento em Turismo Universidade de Aveiro, Portugal.

MINEIRO, C. (org.) (2004). Temas de Museologia: museus e acessibilidade. Instituto Português de Museus - Ministério da Cultura. Facsimile ed., Lisboa.

NEVES, J. (2009). Comunicação multisensorial em contexto museológico. Actas do 1 Seminário de Investigação em Museologia dos países de língua portuguesa e espanhola. Vol. 2, p 180-192.

NEVES, J. (2011). Guia da Audiodescrição: imagens que se ouvem. Instituto Nacional para Reabilitação/Instituto Politécnico de Leiria. 
PRIMO, J. Museologia e design na construção de objectos comunicantes. Caleidoscópio, n. 7, p. 109-115, jul. 2011.

ORGANIZAÇÃO MUNDIAL DE SAÚDE (OMS). Disponível em: <http://portal.mj.gov.br/corde/ normas_abnt.asp>. Acesso em: 10 mar. 2010.

TOJAL, A. (2013). Ação educativa inclusiva e comunicação museológica: mudança de Paradigmas. In: Cadernos Tramas da Memória, n. 3. Disponível em http://www.arteinclusao.com.br/publicacoes/caderno_tramas_da_memoria.pdf

TOKUHAMA-ESPINOSA, T. N. (2008). The scientifically substantiated art of teaching: a study in the development of standards in the new academic field of neuroeducation - mind, brain, and education science. Dissertação para obtenção do grau de Doutor em Filosofia. Capella University.

VALENTE, D. (2010). Os diferentes dispositivos de fabricação de imagens e ilustrações táteis e as possibilidades de produção de sentido no contexto perceptivo dos cegos. In: Revista Educação Arte e Inclusão, v. 02, p. $59-82$.

VIVIAN, D. (2012). Aplicação das diretrizes da ciência da mente, cérebro e educação à produção de vídeos educacionais. Dissertação de Mestrado. Programa de Pós-Graduação em Design. Escola de Engenharia e Faculdade de Arquitetura da Universidade Federal do Rio Grande do Sul.

SANTOS, S. M. A. Acessibilidade em museus. 2009. Dissertação (Mestrado em Museologia) Curso Integrado de Estudos Pós-Graduados em Museologia da Faculdade de Letras da Universidade do Porto, Porto, Portugal, 2009.

SARRAF, V. P. A comunicação dos sentidos nos espaços culturais brasileiros: estratégias de mediações e acessibilidade para as pessoas com suas diferenças. 2013. $251 \mathrm{f}$. Tese (Doutorado em Comunicação e Semiótica) - Programa de Pós-Graduação em Comunicação e Semiótica da Pontifícia Universidade Católica de São Paulo (PUC-SP), São Paulo, 2013. 